2. Dejung B. Die Behandlung unspezifischer chronischen Rückenschmerzen mit manuelle Triggerpunkt-Therapie. [German: Treatment of chronic non-specific low back pain with manual trigger point therapy]. Manuelle Medizin 1999;37:124-131.

3. Hsieh CYJ, Hong CZ, Adams AH, et al. Interexaminer reliability of the palpation of trigger points in the trunk and lower limb muscles. Arch Phys Med Rehabil 2000;81:258-264.

4. Hsieh CY, Adams AH, Tobis J, et al. Effectiveness of four conservative treatments for subacute low back pain: A randomized clinical trial. Spine 2002;27:1142-1148.

5. Itoh, K, Katsumi Y, Kitakoji H. Trigger point acupuncture treatment of chronic low back pain in elderly patients: A blinded RCT. Acupunct Med 2004;22:170-177.

6. Kovacs FM, Abraira V, Pozo F, et al. Local and remote sustained trigger point therapy for exacerbations of chronic low back pain: A randomized, double-blind, controlled, multicenter trial. Spine 1997;22:786-97.

7. Ney JP, Difazio M, Sichani A, Monacci W, Foster L, Jabbari B. Treatment of chronic low back pain with successive injections of botulinum toxin A over 6 months: A prospective trial of 60 patients. Clin J Pain 2006;22:363-369.

8. Raj PP, Paradise LA. Myofascial pain syndrome and its treatment in low back pain. Semin Pain Med 2004;2(3):167-174.

9. Travell JG, Simons DG. Myofascial Pain and Dysfunction: The Trigger Point Manual. Vol. 2. Baltimore, MD: Williams \& Wilkins, 1992.

\title{
Authors' Response to Dr. Simons
}

We would like to thank Dr. Simons for his letter to the editor on our case series titled "Management of low back pain: A case series illustrating the pragmatic combination of treatment- and mechanism-based classification systems". Recent literature has clearly identified the importance of classifying patients with low back pain (LBP) into subgroups ${ }^{1,2}$. Classification provides a means of breaking down a larger entity into more homogenous subgroups of patients based on examination data ${ }^{3}$. The most common methods of classifying patients with musculoskeletal conditions are based on identifying the underlying pathology causing the condition ${ }^{4}$, however the pathology underlying the complaints of LBP is often difficult to identify ${ }^{5}$. Even if identified, the pathology is often of limited usefulness in selecting the most beneficial interventions ${ }^{6}$. Moreover, classification is most helpful for physical therapists when it is based on signs and symptoms that match interventions to the subgroup of patients most likely to benefit from them (i.e. treatment-based classification) ${ }^{7,8}$. The goal of treatment-based classification is to improve decision-making in the determination of an individual patient's diagnosis, prognosis, and intervention strategy.

Dr. Simons seems to ignore the importance of sub-grouping patients when he states that myofascial trigger points are the "treatable cause" of LBP. We disagree with this as it has been reported that in $90 \%$ of patients with LBP a patho-anatomical cause cannot be identified ${ }^{5}$. Additionally, reviewing the references that Dr. Simons provided it appears that Kovacs et a ${ }^{9}$ also contradict Dr. Simons with the following statement, "Low back pain often is believed to be the result of degenerative disk syndrome, protrusion of intervertebral disks, strains, sprains, and other disorders associated with the position or movement of the spine, such as those caused by scoliosis or spondylolisthesis. In most cases, however, it is not possible to establish an organic cause." In another reference provided by Dr. Simons we find that the first randomized controlled trial performed to evaluate the effectiveness of myofascial therapy clearly demonstrated that no significant differences existed for pain or activity between patients receiving myofascial therapy, joint manipulation, and back school in the management of sub-acute LBP ${ }^{10}$. We would argue that the lack of statistical significance may have been related to the failure of the authors to classify patients to receive interventions from which they are most likely to benefit. Nonetheless this provides no data to support the use of incorporating the treatment of myofascial trigger points into the management of LBP.

In our case series therapists categorized patients into subgroups and then delivered interventions that provided patients with the highest likelihood of recovery. In addition to the utilization of a treatment-based classification therapists also treated individual impairments. At this point in our case series it would have been appropriate for the clinicians to treat trigger points that they found, however none of the clinicians chose to do so. Despite not treating any trigger points, our patients' exhibited clinically meaningful improvements in all outcomes. Additionally, a number of trials ${ }^{1,2,8,11-14}$ demonstrating the effectiveness of conservative interventions for the management of LBP have shown statistically significant improvements in pain and disability despite none of the patients receiving any treatments directed at myofascial trigger points. We agree with Dr. Simons that his textbook provides a detailed description on how to treat myofascial trigger points. However, the aforementioned references challenge the need to do so.

We have found little support for the use of soft tissue mobilization and treatment of trigger points in the (sub) acute LBP population ${ }^{15,16}$. Within the limitations imposed by current best evidence for the (sub) acute LBP population it is our opinion that if clinicians choose to incorporate any soft tissue or trigger point techniques that these should be used within the context of a treatment-based classification system that is supported in the literature.

Daniel Pinto, PT, OCS

Joshua Cleland, PT, PhD, OCS, FAAOMPT

E70 / The Journal of Manual \& Manipulative Therapy, 2007 


\section{REFERENCES}

1. Brennan GP, Fritz JM, Hunter SJ, Thackeray A, Delitto A, Erhard RE. Identifying subgroups of patients with acute/subacute "nonspecific" low back pain: Results of a randomized clinical trial. Spine 2006;31:623-631.

2. Fritz JM, Delitto A, Erhard RE. Comparison of classification-based physical therapy with therapy based on clinical practice guidelines for patients with acute low back pain: A randomized clinical trial. Spine 2003;28:1363-1371.

3. Buchbinder R, Goel V, Bombardier C, Hogg-Johnson S. Classification systems of soft tissue disorders of the neck and upper limb: Do they satisfy methodological guidelines? J Clin Epidemiol 1996;49:141-149.

4. Leboeuf-Yde C, Lauritsen JM, Lauritzen T. Why has the search for causes of low back pain largely been nonconclusive? Spine 1997;22:877-881.

5. Abenhaim L, Rossignol M, Gobeille D, Bonvalot Y, Fines P, Scott S. The prognostic consequences in the making of the initial medical diagnosis of work-related back injuries. Spine 1995;20:791-795.

6. Waddell G. Low back pain: A twentieth century health care enigma. Spine 1996;21:2820-2825.

7. Rose SJ. Physical therapy diagnosis: Role and function. Phys Ther 1989;69:535-537.

8. Fritz JM, Brennan GP, Clifford SN, Hunter SJ, Thackeray A. An examination of the reliability of a classification algorithm for subgrouping patients with low back pain. Spine 2006;31:77-82.

9. Kovacs FM, Abraira V, Pozo F, et al. Local and remote sustained trigger point therapy for exacerbations of chronic low back pain: A randomized, double-blind, controlled, multicenter trial. Spine 1997;22:786-797.

10. Hsieh CY, Adams AH, Tobis J, et al. Effectiveness of four conservative treatments for subacute low back pain: A randomized clinical trial. Spine 2002;27:1142-1148.

11. Childs JD, Fritz JM, Flynn TW, et al. A clinical prediction rule to identify patients with low back pain most likely to benefit from spinal manipulation: A validation study. Ann Intern Med 2004;141:920-928.

12. Flynn T, Fritz J, Whitman J, et al. A clinical prediction rule for classifying patients with low back pain who demonstrate short-term improvement with spinal manipulation. Spine 2002;27:2835-2843.

13. Hicks GE, Fritz JM, Delitto A, McGill SM. Preliminary development of a clinical prediction rule for determining which patients with low back pain will respond to a stabilization exercise program. Arch Phys Med Rehabil 2005;86:1753-1762.

14. Long A, Donelson R, Fung T. Does it matter which exercise? A randomized control trial of exercise for low back pain. Spine 2004;29:2593-2602.

15. Yip YB, Tse SH. The effectiveness of relaxation acupoint stimulation and acupressure with aromatic lavender essential oil for non-specific low back pain in Hong Kong: A randomised controlled trial. Complement Ther Med 2004;12(1):28-37.

16. Furlan AD, Brosseau L, Imamura M, Irvin E. Massage for low back pain. Cochrane Database Syst Rev 2002.

\section{LETTER TO THE EDITOR}

\section{Low Back Pain and Leg Symptoms: Another Differential Diagnostic Possibility}

This letter is in response to the recent article by Pinto et a $\mathrm{l}^{1}$. The authors are to be congratulated on a very successful presentation of a case series. My comments are directed at some of the symptoms of patients 1 and 2, because they apply to other clients seen in a typical PT clinic. Patient 1 had chief complaints of low back and groin pain, whereas patient 2 reported left buttock pain and pins and needles down the left medial leg. The examination addressed many things, including testing for altered sensation to pinprick in the lower extremity dermatomes. However, I would like to suggest that for these and similar patients the inclusion of the lower abdominal wall in the sensory screen might be of value because of the possibility of a para-inguinal neuropathy.

A recent male patient had experienced painful traumatically induced neuropathies of 33 years duration involving the accessory obturator, ilioinguinal, and iliohypogastric nerves and the genital portion of the genitofemoral and vesicular portion of the hypogastric nerves. All these nerves are involved in the sensory innervation of the lower abdominal wall and genito-urinary region, but may also cause hypersensitivity in the groin and paraesthesiae and/or dysaesthesia in the medial calf (saphenous portion of femoral sensory nerve). Sensory alterations in the saphenous distribution of the medial leg are at times misinterpreted due to its overlap with the S1 dermatome. In this patient a reduced sensation to pin prick was not present but rather sensory hyperaesthesia and allodynia were noted in the lower abdominal and lower extremity dermatomes.

Of differential diagnostic importance is that the ilioinguinal and iliohypogastric nerves and the genital portion of the genitofemoral nerve can be palpated proximal to and/or within the inguinal canal. All three nerves take a primary origin from the T12-L2 nerve roots. The ilioinguinal nerve innervates the inguinal ligament, the anterior inner wall of the inguinal canal, and the spermatic cord and can be palpated within and outside the inguinal canal. The iliohypogastric nerve supplies the roof of the inguinal canal and innervates superficial skin. The genital portion of the genitofemoral nerve-despite its very small diameter - can be screened by applying pressure onto the floor of the inguinal canal, located at the top of the pubic bone just medial to the spermatic cord. There is however, considerable variation in the pathway of this nerve. These palpatory tests have 